\title{
DEMOGRAPHIC CHANGES AND VISUAL DISABILITY AND EASTERN BULGARIA
}

\author{
Binna Nencheva \\ Department of Ophthalmology and Visual Sciences, Medical University of Varna
}

\begin{abstract}
INTRODUCTION: Age and gender are among the risk factors influencing the disability.

PURPOSE: To study the connection between the demographic changes in Eastern Bulgaria and frequency of disability.

MATERIAL AND METHODS: The blindness and poor vision were evaluated retrospectively and calculated per population of $100 \mathbf{0 0 0}$. All information was obtained from the National Statistical Institute and the Specialized Visual Labor Expert Medical Commission - Varna registry for the period 2005-2012, filled in a specifically designed data collection form, and subsequently processed with SPSS 20.

RESULTS AND DISCUSSION: The data from the NSI shows an increase of the population above 60 years of age from 2009. The individuals up to 19 years of age are $4.90 \%$, and those of 20 years of age and above are $95.19 \%$. The primary disability (PD) starts to increase after the age of 60 and decreases to a small extent within the age group above 80 years. The majority of the patients are city residents. Regarding the gender indicator it has been demonstrated that contrary to monocular blindness where the male PD prevails, for binocular blindness above the age of 80 the PD women are more affected.
\end{abstract}

CONCLUSIONS: PD for individuals with visual conditions increases in correlation with general tendency of the population ageing.

Keywords: disability, Eastern Bulgaria, demographic changes

\section{INTRODUCTION}

Age is one of the main risk factors for the development of eye pathology leading to blindness and considering the demographic situation in Bulgaria, an increase in the severe eye diseases should be expected. Demographic processes in our country are characterized by a continued trend of a population decrease and its ageing related to low birth rate, in-

\footnotetext{
Address for correspondence:

Binna Nencheva

Specialised Eye Hospital - Varna

15 Doiran Str.

9000 Varna, Bulgaria

e-mail:bnenkova@gmail.com
}

Received: August 20, 2015

Accepted: August 31, 2015 crease in death rate and immigration of a significant part of the young people. The longer life duration of women is a prerequisite for the higher morbidity rate and increasing disability.

\section{MATERIAL AND METHODS}

The blindness and poor vision were evaluated retrospectively and calculated per population of 100 000. All information was obtained from the National Statistical Institute and the Specialized Visual Labor Expert Medical Commission - Varna registry for the period 2005-2012, filled in a specifically designed data collection form. The dynamics of the demographic changes were presented based on data from the National Statistical Institute. The data were coded in an Excel spreadsheet and processed with SPSS 20. 


\section{RESULTS}

The data from the NSI shows an increase of the population above 60 years of age from 2009. The individuals up to 19 years of age are $4.9 \%$, and those of 20 years of age and above are $95.19 \%$. The primary disability (PD) starts to increase after the age of 60 and decreases to a small extent within the age group above 80 years. The majority of the patients are city residents. Regarding the gender indicator it has been demonstrated that contrary to monocular blindness where the male PD prevails, for binocular blindness above the age of 80 the PD is higher amongst females.

Eastern Bulgaria has a territory of approximately 30000 sq.km and a population of approximately 1800000 persons for the period 2005-2012 г. (Fig. 1).

The data presented on Figure 1 shows that there is a decrease trend of the population of the examined region.

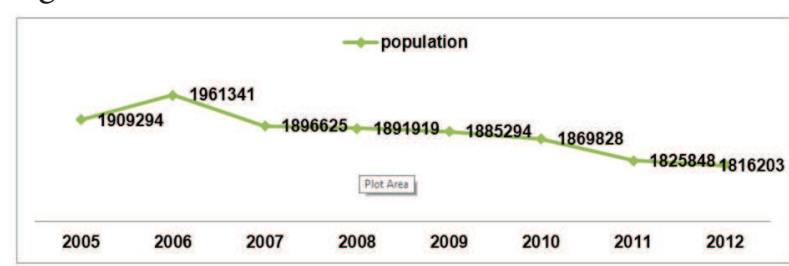

Fig. 1. Population dynamics 2005-2012 for Eastern Bulgaria

The gender distribution shows prevail of women during the entire period which coincides with the general decrease trend which is more visible after 2010 (Fig. 2).

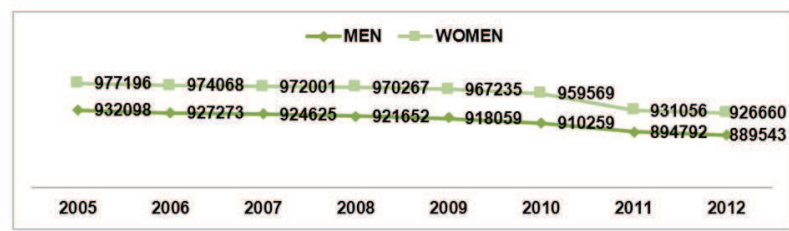

Fig. 2. Gender distribution of Eastern Bulgaria population (number)

The population dynamics in terms of place of residence shows a gradual decrease trend both in the big and small settlements (Fig. 3.).

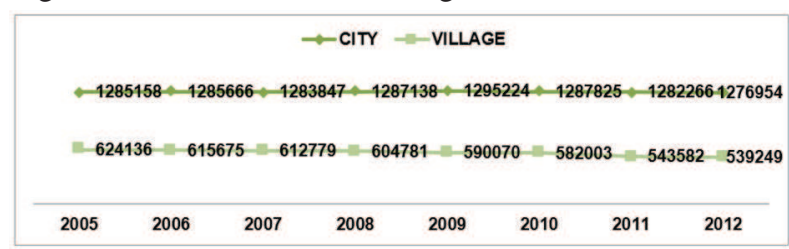

Fig. 3. Population dynamics by place of residence

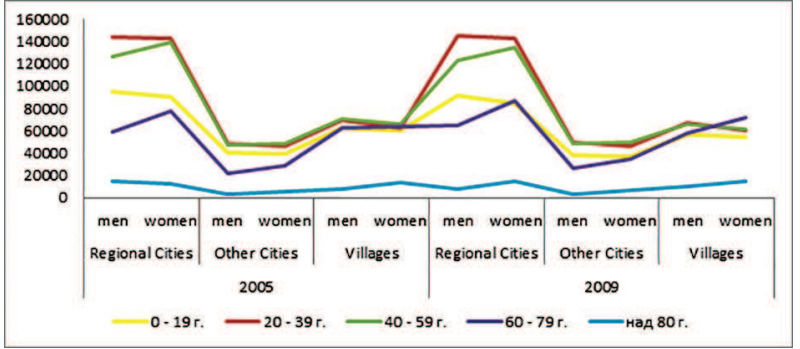

Fig. 4. Population dynamics by age, gender and place of residence for 2005 and 2009 (data by NSI)

The results presented on Fig. 4 show that in 2009 there is a decrease trend of the individuals in active age and an increase of the individuals of above 60 years of age.

Expert decisions regarding initially certified patients with blindness and low vision of the Specialized Visual Labor Expert Medical Commission Varna for the period from January 2005 to December 2012 have been analyzed and based on the clinical grounds, the data was drawn based on the age (Fig. 5), place of residence (Fig. 6), visual acuity with complete correction and the leading diseases for every individual - binocular blind men: 912, women: 935, total : 1847; monocular blindness: men: 915 , women: 716, total: 1631 (3478).

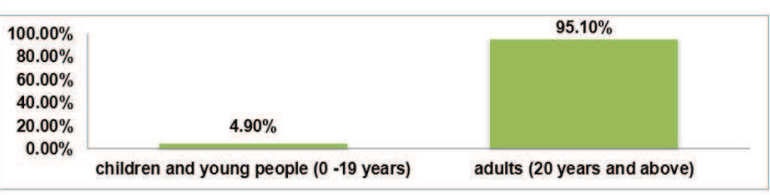

Fig. 5. Distribution by age groups

There is a significant difference in the certified patients in both age groups $(\mathrm{p}<0.05)-4.90 \%$ and 95.19\% (Fig. 5).

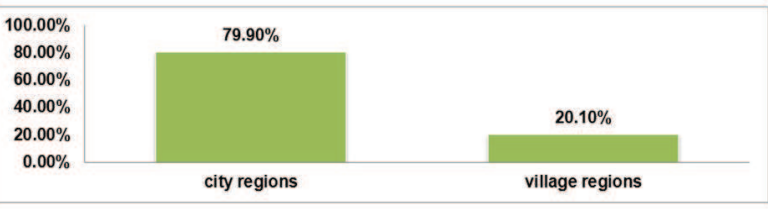

Fig. 6. Distribution by place of residence

As seen from Fig. 6 the city residents prevail (79.90\%). 

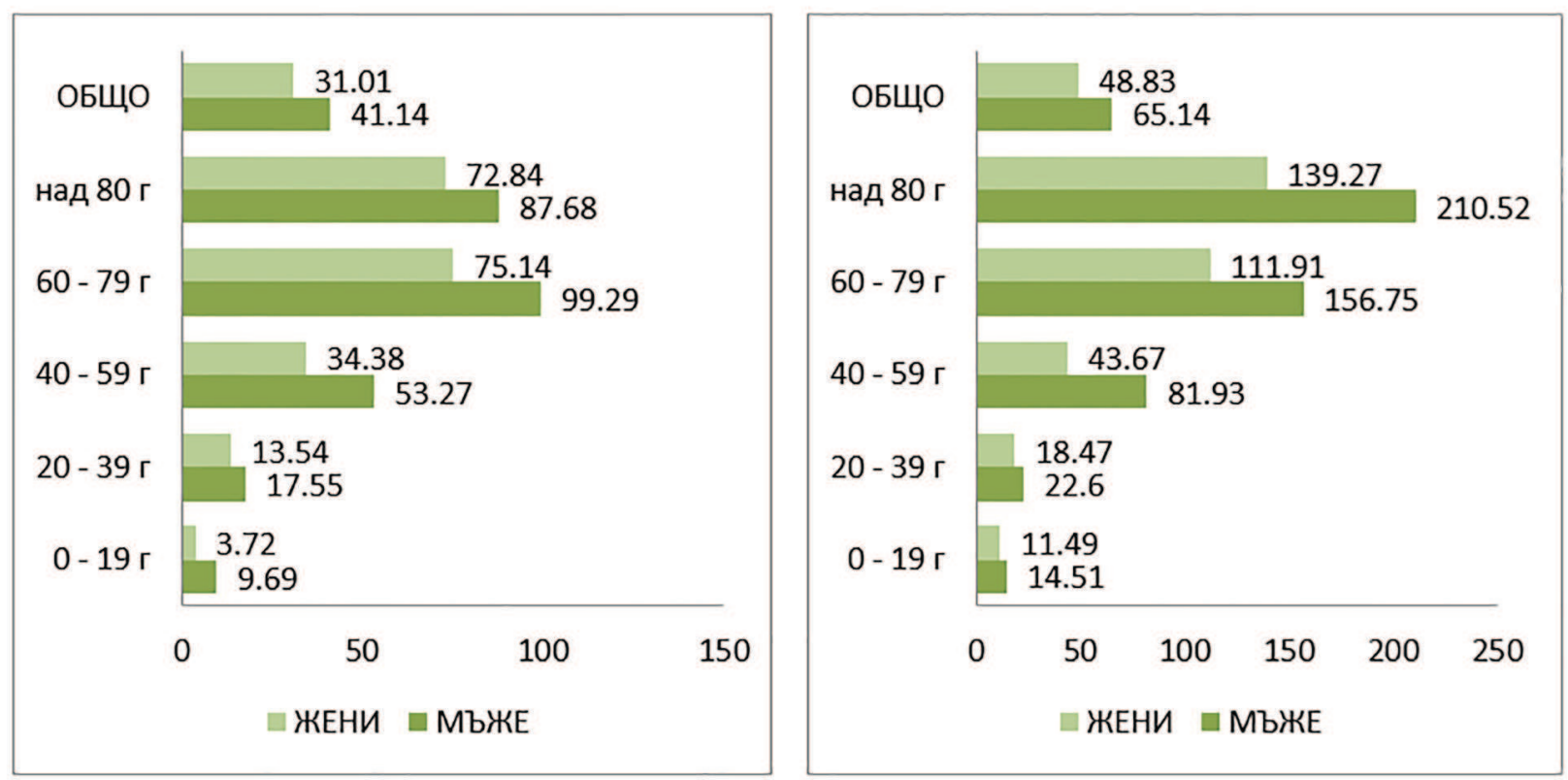

Fig. 7. Monocular blindness - distribution by gender, age and period of observation - PD (primary disability per 100000 individuals)

Men are characterized by higher values of PD compared to women for both periods $(\mathrm{p}<0.05)$, which give us a reason to consider that men are more affected by diseases leading to monocular blindness (Fig. 7).

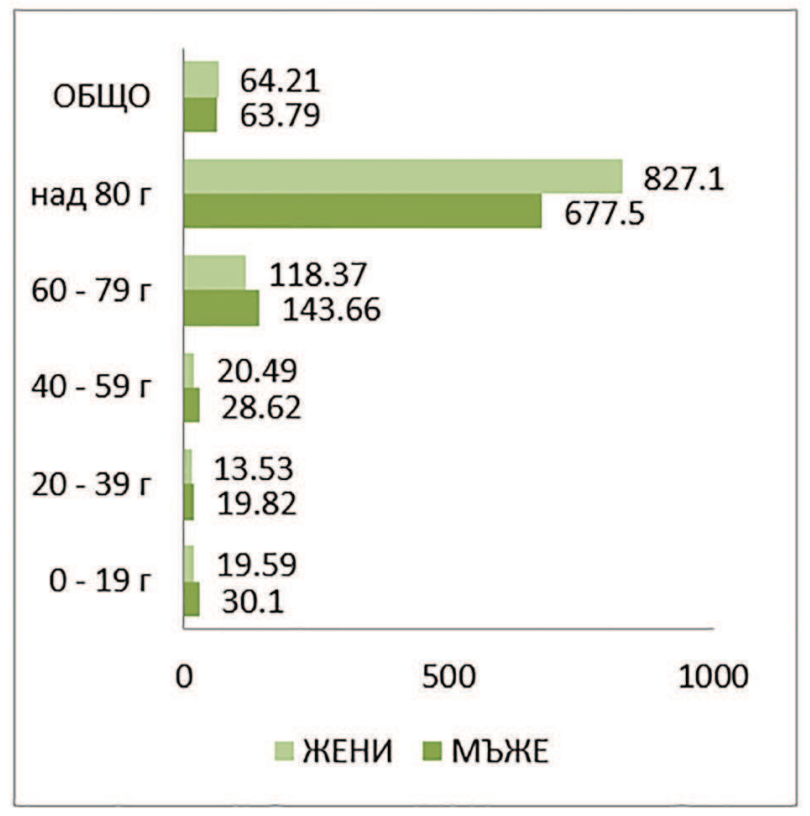

The distribution by gender also does not show a significant difference for the entire period of observation which is a proof that both men and women are equally affected by a pathology leading to poor vision.

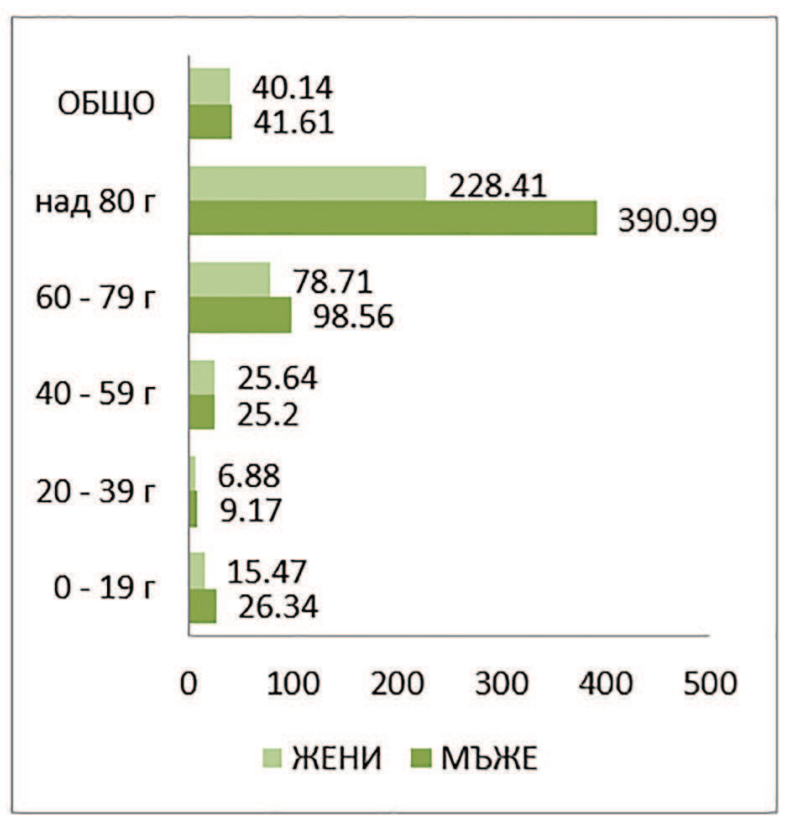

Fig. 8. Binocular blindness - distribution by gender, age and period of observation - PD (primary disability per 100000 individuals) 
The PD starts to increase after the age of 60 and decreases to a small extent in the age group of 80 years (Fig. 8 )

Regarding the gender indicator it is demonstrated that contrary to monocular blindness where the PD prevails amongst men, for binocular blindness, after the age of 80 years it begins to prevail for women $(\mathrm{p}<0.05)$, which gives us the reason to presume that on one hand women after the age of 80 years prevail in terms of binocular blindness and on the other hand - that the duration of life of women is also a prerequisite for the $\mathrm{PD}$ increase in this age group (Fig.8).

\section{DISCUSSION}

Bulgaria follows the general world trend for ageing of the population as the data provided by the NSI suggests and respectively for the increase of the disability related to third age diseases according to the data presented by the expert decision of the Labor Expert Medical Commission. The depopulation of villages and the prevalence of residents above 60 years of age increase the PD of this category of individuals, regardless that the data shows a bigger percentage for city residents which is associated with internal migration.

The relative share of the individuals above 65 years of age increases and in 2001 it is $16.8 \%$, and in 2011-18.5\%. For 2001 the share of the individuals below 15 years is $15.3 \%$ and in 2011 it is $13.2 \%$. The average age of the population for 2009 is 41.8 , and the ageing process is more expressed in the villages -45.5 compared to 40.3 in the cities. In 2010 every fourth village resident is above 65 years of age. Women prevail within the higher age group. The average life duration for men is 69.90, and for women it is 77.08 (2). The main problem resulting from this data is the increase in age related pathology. One of the main factors affecting health is the socio-economic status unemployment, poverty. There is a clearly expressed connection between income and the unsatisfactory consumption of health services, untimely and improper treatment and this leads to chronic diseases and the appearance of irreversible changes which put these patients in the disabled persons group.

According to data provided by the National Eye Institute 2004 (12) 3.3 millions of people have blindness and poor vision in the USA in the age group above 40 years and it is expected that by 2020 they will be 5.5 millions. Based on modern epidemiological data in France most affected are the individuals above 60 years of age - $16.6 \%$ (14), followed by those in Germany $10.6 \%$ (4) - non-proliferative diabetic retinopathy. All epidemiological studies show an increase of the disease frequency with the increase of age $(5,7)-1.7 \%$, proliferative $-0.6 \%$ diabetic retinopathy. In Bulgaria according to Vassileva et al. agerelated macular degeneration is the reason for $20 \%$ of the blindness of the Bulgarians above 40 years of age (13). Glaucoma can be found at $1.2 \%$ of the white population above 40 years of age and increases to $5 \%$ for the individuals above 70 years of age. A five-year study conducted by Anhchuong Le et al 2003 (2) establishes that there is a significant risk of primary open-angle glaucoma after the age of 60 and it increases with every decade. Such age-related trend has been found also within the Barbados Incidence Eye Study (9) and in some other studies $(6,10,11,15)$, but not in the Delby Sweden Study (3). The age increase leads to a cumulative effect of other risk factors which make the optic nerve more vulnerable (9).

The Beaver Dam Study (8) provides the following data on cataract: the frequency of the nuclear, cortical and posterior subcapsular cataract is $1.5 \%$, $1.5 \%$ and $1.6 \%$ for patients aged between $43-54$ years and it increases to $57 \%, 42.4 \%$ and $14.3 \%$ for the age of 75 years respectively.

\section{CONCLUSIONS}

The presented data highlighted that the disability is increasing and this is related to the ageing of the population. This does not mean that the eye disability as a problem is unsolvable. One possible measure is routine preventive examinations of all people above 60 years regarding their social status and site of residence.

\section{REFERENCES}

1. Ministry of Labor and Social Policy. Actualization of the national strategy on the demographic development of the population of the Republic of Bulgaria (2012-2030). Sofia.

2. Anhchuong Le, Bickol NM, Catherine AM, Hugh R. Risk factors associated with the incidence of open-angle glaucoma: The Visual Impairment Project. Ivest Ophthalmol \& Vis Science 2003;44(9):3783-9. 
3. Bengtsson B. Incidence of manifest glaucoma. Br J Ophthalmol 1989;73:483-487.

4. Blum R, Kloos C, Muller N, Mandecka A, Berner R, Bertram B, Muller U. A Prevalence of diabetic retinopathy. Check-up program of a public health insurance company in Germany, 2002-2004. Ophthalmology. 2007;104:499-500.

5. Bressler SB, Munoz B, Solomon SD, West SK. Racial differences in the prevalence of age-related macular degeneration; the Salisbury Eye Evaluation (SEE) Project. Arch Ophthalmol 2008 Feb;126(2):241-5.

6. Dielemans I, Vingerling JR, Wolf RCW, et al. The prevalence of primary open angle glaucoma in a population - based study in the Netherlands: The Rotterdam Study. Ophthalmology. 1994;101:1851-1855.

7. Klein R, Klein BE, Knudtson MD, Meuer SM, Swift $M$, Gangnon, RE. Fifteen-year cumulative incidence macular degeneration: the Beaver Dam Eye Study. Ophthalmology 2007 Feb;114(2): 253-62.

8. Klein BE, Klein BE, Linton KL. Prevalence of agerelated lens opacities in a population. The Beaver Dam Eye Study. Ophthalmology. 1992;99:546-52.

9. Leske MC, Connell AM, Wu Sy, et al. Incidence of open -angle glaucoma: the Barbados Eye Studies. The Barbados Eye Studies Group. Arch Ophthalmol. 2001;119:89-95.

10. Leske MC, Connell AM, Wu Sy, et al. Risk factors for open-angle glaucoma: The Barbados Eye Study Arch Ophthalmol 1995;113:918-924.

11. Mitchell P, Smith W, Atteb K, Heale PR. Prevalence of open-angle glaucoma in Australia: the Blue Mountains Eye study. Ophthalmology. 1996;103:1661-1669.

12. National Eye Institute. Vision loss from eye diseases will increase as Americans age. April 12, 2004. Arch Ophthalmol. 2001; 119:89-95.

13. Vassileva P, Giesser SC, Vitale S, Cholakova T, Katz J, West S. Blindness and visual impairment in Western Bulgaria. Ophthalmic Epidemiol. 1996 Dec;3(3):143-9.

14. Waked N, Saad A, Mehanna C, Sleilary G, Kortbaoui R. Prevalence causes and risk factors for blindness and visual impairment among nursing home residents in Lebanon. J Fr Ophthalmol. 2007;30:497-502.
15. Weih LM, Mukesh N, McCarty CA, Taylor HR. Prevalence and predictors of open-angle glaucoma: results from the Visual Impairment Project. Ophthalmology. 2001;108:1966-1972.

Scripta Scientifica Medica, vol. 47, No 3, 2015, pp. 43-47 